04,08

\title{
Парамагнитные антисайт Мn-дефекты в нанокерамике алюмомагниевой шпинели
}

\author{
() А.Ф. Зацепин ${ }^{1}$, А.Н. Киряков ${ }^{1, \uparrow}$, Д.Р. Байтимиров ${ }^{1}$, Т.В. Дьячкова ${ }^{2}$, А.П. Тютюнник ${ }^{2}$, Ю.Г. Зайнулин ${ }^{2}$ \\ ${ }^{1}$ Уральский федеральный университет, \\ Екатеринбург, Россия \\ ${ }^{2}$ Институт химии твердого тела УрО РАН, \\ Екатеринбург, Россия \\ I E-mail: arseny.kiriakov@urfu.ru
}

Поступила в Редакцию 16 августа 2019 г.

В окончательной редакции 16 августа 2019 г.

Принята к публикации 3 сентября 2019 г.

\begin{abstract}
Исследовано влияние структурных и размерных факторов на формирование собственных и примесных парамагнитных центров в нанокерамиках алюмомагниевой шпинели. Исследуемые образцы (с размером зерен $\sim 30 \mathrm{~nm}$ ) были получены методом термобарического синтеза. В качестве эталонов были использованы микрокристаллическая керамика и монокристалл $\mathrm{MgAl}_{2} \mathrm{O}_{4}$. В монокристалле и микрокерамике присутствуют характерные парамагнитные центры $\mathrm{Mn}^{2+}$ (константа сверхтонкой структуры (CTC) $\left.A=82 \mathrm{G}\right)$. В исследуемых образцах нанокерамики в исходном состоянии регистрируются как примесные $\mathrm{Mn}^{2+}$ так и собственные $F^{+}$-центры. В отличие от нанокерамики в эталонных образцах центры типа $\mathrm{F}^{+}$возникают только после облучения $130 \mathrm{keV}$ ускоренными электронами. Параметры $\mathrm{Mn}^{2+}$ центров в нанокерамике существенно отличаются от таковых в микрокерамике и монокристалле. Для $\mathrm{Mn}^{2+}$-центра в нанокерамике ЭПР сигнал характеризуется двумя аномальными константами СТС $\left(A_{1}=91.21 \mathrm{G}, A_{2}=87.83 \mathrm{G}\right)$, обусловленными двумя разновидностями октаэдрически координированных ионов марганца (антисайт дефектов $\left[\mathrm{Mn}^{2+}\right]_{\mathrm{Al}^{3+}}$ ). Особенности спектральных параметров марганцевых центров коррелируют с уменьшением параметра решетки $\mathrm{MgAl}_{2} \mathrm{O}_{4}$ в наноструктурном состоянии. Наблюдаемые эффекты интерпретируются на основе предположенной схемы зарядовой компенсации $\left[\mathrm{Mn}^{2+}\right]_{\mathrm{Al}}$ алюминиевым антисайт дефектом и $F^{+}$-центром.
\end{abstract}

Ключевые слова: Электронный парамагнитный резонанс, $\mathrm{MgAl}_{2} \mathrm{O}_{4}$, нанокерамика, микрокерамика, сверхтонкая структура, антисайт дефекты.

DOI: 10.21883/FTT.2020.01.48744.568

\section{1. Введение}

Интенсивное развитие фотоники и электроники диктует необходимость разработки новых функциональных материалов с особыми свойствами, такими как высокая радиационная стойкость, прозрачность в широком спектральном диапазоне, термостабильность. Керамика алюмомагниевой шпинели является одним из наиболее радиационно-стойких материалов, о чем свидетельствуют многие работы по облучению шпинели электронами, нейтронами, ионами различных энергий [1-7]. Шпинель также является привлекательным материалом для ее легирования переходными $3 d$-элементами, а также редкими землями, с целью получения желаемых оптических свойств (поглощение, люминесценция) [8-11].

В результате высокоэнергетического воздействие на кристаллическую структуру шпинели (ионая имплантация, ускоренные электроны, быстрые нейтроны, термобарические воздействия) образуются как собственные так и примесные дефекты, с локальным возмущением кристаллического поля. Четкое представление влияния примесных и собственных дефектов на матрицу алюмомагниевой шпинели играет важную роль в понимании механизмов дефектообразования и их микроскопических параметров.
Известно, что нейтронная или онная бомбардировка алюмомагниевой шпинели $\left(\mathrm{MgAl}_{2} \mathrm{O}_{4}\right)$ стимулирует образование дефектов анионной подрешетки - $V_{\mathrm{O}}[1-3]$. Такие анионные дефекты могут наводится также в результате термохимического окрашивания [12] Анионные вакансии выступают в качестве эффективных ловушек электронов. В результате захвата одного, или двух электронов анионной вакансией происходит частичная или полная зарядовая компенсация, с образованием $F^{+}$. и $F$-центров соответственно. Захват одного неспаренного электрона характеризуется в спектрах электронного парамагнитного резонанса полосой поглощения с $g$-фактором $\sim 2.003$ [1]. Особенности изменения ЭПР-сигнала с участием $F^{+}$-центра в монокристалле подробно описана в работе [13]. Однако поведение $F^{+}$-центров в синтезированных керамиках изучено слабо и требует подробного рассмотрения.

Катионная подрешетка шпинели состоит из двух сортов катионов, вследствие чего образуется 2 типа катионных подрешеток алюминиевая и магниевая. Алюминиевые катионы находятся в октаэдрическом окружении кислорода, тогда как магниевые в тетраэдрическом. Между этими двумя типами подрешеток под высокоэнергетическим воздействием (нейтронное, электронное, ионное облучение, термобаричечкие воз- 
действия) возможно образование дефектов катионного перемешивания (антисайт дефекты, ADs). Такие дефекты представляют собой ион алюминия в положении магния $\left[\mathrm{Al}^{3+}\right]_{\mathrm{Mg}^{2+}}$ и наоборот. Зарядовая компенсация в данном случае осуществляется путем образования пары таких дефектов $\left[\mathrm{Al}^{3+}\right]_{\mathrm{Mg}^{2+}}$ и $\left.\mathrm{Mg}^{2+}\right]_{\mathrm{Al}^{3+}}$ таким образом, что в целом сохраняется нейтральность в кристаллической решетке [14]. В керамиках, синтезированных в результате термобарической обработки, дефекты катионного перемешивания присутствуют в большем количестве, в следствие закалки неравновесного состояния системы под высоким давлением в результате быстрого снятия давления и температуры $[15,16]$. Исследования парамагнитных особенностей монокристаллической AMШ c ADs показали, что такие центры не обладают резонансным поглощением электромагнитной энергии в магнитном поле, но могут в значительной степени искажать сигнал присутствующих рядом парамагнитных центров (например, $F^{+}$-центров) [13]. Вопрос о роли собственных дефектов анионной и катионных подрешеток или же примесных центров в ЭПР-спектре нанокерамик остается открытым.

Примесные дефекты в шпинели чаще всего представлены ионами $3 d$-элементов, с характерными спектральными особенностями, вызванными неэкранированной $3 d$-оболочкой. Под воздействием различного рода облучений или сильных восстановителей, или больших механических нагрузок в матрице происходит искажение локального окружения $3 d$-иона. В результате, спектральные характеристики $3 d$-ионов изменяются, что позволяет использовать их в качестве индикаторов кристаллического поля. Например, внедрение в матрицу АМШ примесных ионов $\mathrm{Mn}^{2+}$ дает набор характерных линий сверхтонкого расщепления (СТС) в спектрах ЭПР за счет взаимодействия магнитного момента неспаренного электрона с магнитным моментом ядра. Поскольку спин ядра $\mathrm{Mn}^{2+} I=5 / 2$, то под действием магнитного поля $\mathbf{H}$ магнитный момент ядра примет $2 I+1=6$ значений. Таким образом, на электронный магнитный момент будут действовать шесть различных значений Н. В таком поле магнитный момент электрона $\mu s$ будет обладать шестью возможными значениями энергии. В результате каждый зеемановский электронный подуровень расщепится на шесть подуровней сверхтонкой структуры. $(2 S+1)$. Результирующее количество энергетических уровней будет 36 , исходя из: $(2 I+1) \times(2 S+1)$. Используя соответствующие магнитные квантовые числа для спина электрона $M$ и спина ядра $m(-S \leq M \leq S,-I \leq m \leq I)$ возможны 5 разрешенных электрон-спиновых перехода для $\Delta M s= \pm 1 ; \Delta m_{I}=0:|5 / 2 m\rangle \leftrightarrow|3 / 2 m\rangle,|3 / 2 m\rangle \leftrightarrow|1 / 2 m\rangle$, $|-1 / 2 m\rangle \leftrightarrow|-3 / 2 m\rangle, \quad|-3 / 2 m\rangle \leftrightarrow|-5 / 2 m\rangle \quad$ и $|1 / 2 m\rangle \leftrightarrow|-1 / 2 m\rangle$. Однако ввиду сильной угловой зависимости первых четырех переходов как в порошковых образцах, так и в керамиках возможно зарегистрировать лишь $|1 / 2 m\rangle \leftrightarrow|-1 / 2 m\rangle$ электронный переход [17].

Известно, что константа СТС линий марганца крайне чувствительна к параметрам решетки [18]. Одним из возможных факторов, оказывающих значительное влияние на параметры решетки АМШ, является метод ее получения и размер кристаллитов. Ввиду чего исследование спектров ЭПР в диапазоне СТС $\mathrm{Mn}^{2+}$ в матрице шпинели, полученной в результате различных методов синтеза, позволит глубже понять фундаментальные особенности взаимодействия примесного иона марганца с матрицей.

Цель настоящей работы заключалась в изучении парамагнитных центров собственных и примесных дефектов, микро- и наномодификации керамик АМШ. Были решены следующие задачи: получение ЭПР спектров нанокерамики и эталонов до и после облучения $130 \mathrm{keV}$ ускоренными электронами; исследование характеристик насыщения различных сигналов ЭПР; анализ полученных результатов.

\section{2. Материалы и методы исследования}

Образцы нанокерамики получены методом термобарической закалки нанопорошка АМШ в Институте химии твердого тела УрО РАН. Содержание примесей переходных элементов в исследуемых микро- и нанокерамиках находится в пределах норм, регламентируемых соответствующими документами на нитрат магния и алюминия (ГОСТ 11088-75, ГОСТ 3757-75). Информацию по режимам синтеза и аттестации образцов можно найти в [19]. Микрокерамики со следовыми примесями $\mathrm{Mn}^{2+}$ предоставлены Санкт-Петербургским университетом им. Петра Великого. Природный монокристалл $\mathrm{MgAl}_{2} \mathrm{O}_{4}$ с примесью $\mathrm{Mn}^{2+}$ предоставлен институтом геологии и геохимии УрО РАН.

Аттестация микро- и нанокерамики выполнена с использованием рентгеновской порошковой дифракции на просвет. Измерения проводились при комнатной температуре на дифрактометре STADI-P оснащенном линейным мини ПЗС-детектором. Рабочее излучение $\mathrm{Cu} K_{\alpha}^{1}$, измерение в диапазоне от 5 до $120^{\circ}$ с шагом $0.05^{\circ}$. В качестве стандарта измерения был использован поликристаллический кремний $(a=5.43075$ (5) $\AA)$. Поиск и идентификация примесных фаз выполнена с помощью библиотеки стандартов ICDD, USA, Release 2016. Постоянная решетки и значение микронапряжений шпинели уточнены методом Ритвельда на основании данных РФА и программного обеспечения GSAS [20,21]. Результаты рентгенофазового анализа микро- и нанокерамики сведены в табл. 1. Значения постоянной решетки для образца природного монокристалла составляет $8.089 \AA$ согласно литературным данным [22].

Спектры ЭПР получены на спектрометре ELEXSYS 580 (Bruker) c резонансной частотой $9.87 \mathrm{GHz}$ ( $X$-band) при комнатной температуре. Сигнал кварцевой пробирки фирмы Bruker учтен. Проведена нормировка ЭПР-сигнала на массу образцов.

Облучение ускоренными электронами выполнено на импульсном линейном ускорителе РАДАН-ЭКСПЕРТ с энергией электронов $130 \mathrm{keV}$, плотностью тока $60 \mathrm{~A} / \mathrm{cm}^{2}$. Время импульса $1 \mathrm{~ns}$. Флюенс при этом составил $\sim 2.4 \cdot 10^{11} \mathrm{~m}^{-3}$. 
Таблица 1. Структурные характеристики исследуемых образцов

\begin{tabular}{c|c|c|c}
\hline Объект & $\begin{array}{c}\text { Постоянная } \\
\text { решетки, } a \AA\end{array}$ & $\begin{array}{c}\text { Область когерентного } \\
\text { рассеяния (ОКР), nm }\end{array}$ & Микронапряжения \\
\hline Нанокерамика & $8.0844(1)$ & $30(2)$ & 0.00092 \\
Микрокерамика & $8.0856(1)$ & $180(5)$ & 0.00013
\end{tabular}

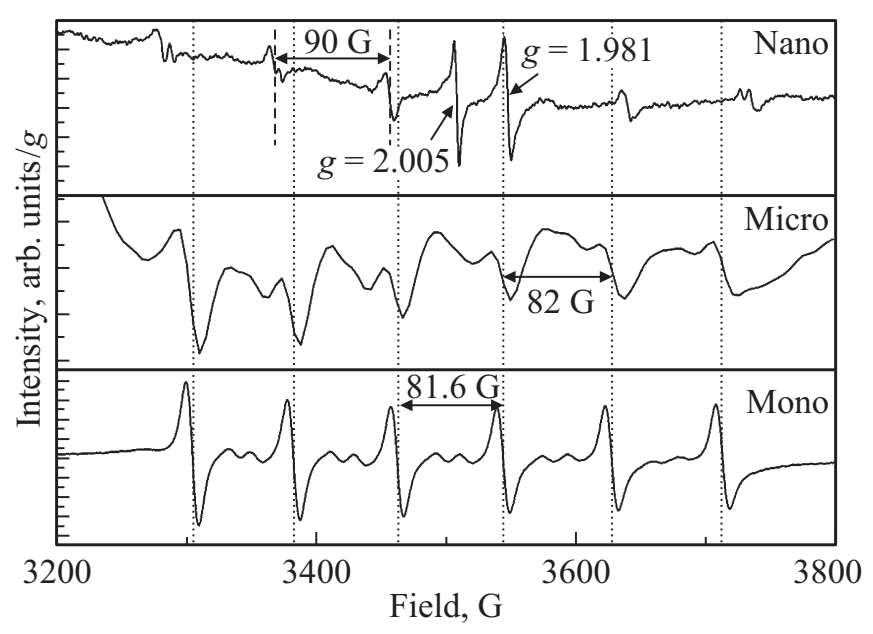

Рис. 1. Спектры ЭПР монокристаллического образца (Mono), микрокерамики (Micro) и нанокерамики (Nano) АМШ. Пунктирными линиями показаны полосы характерные для СТС иона $\mathrm{Mn}^{2+}$ в монокристалле.

\section{3. Результаты}

Сигнал ЭПР образцов нанокерамики, а также эталонов представлен на рис. 1. Во всех образцах в ЭПР спектре регистрируется сигнал сверхтонкой структуры (СТC) ионов $\mathrm{Mn}^{2+}$. Амплитуда сигнала СТС наибольшая в природном монокристалле, что объясняется, вопервых, большей концентрацией примесного марганца, во-вторых крайне низкой дефектностью образца.

Положения линий СТС примесного $\mathrm{Mn}^{2+}$ в образце микрокерамики совпадает с положением СТС в природном монокристалле. Между линиями сверхтонкой структуры наблюдаются пары линий запрещенных переходов [17]. В спектре ЭПР-эталонов в исследуемом диапазоне не регистрируются дополнительные полосы. Однако в нанокерамике наблюдаются дополнительные линии поглощения с $g=2.005$ и $g=1.981$, положение которых характерно для $F^{+}$-центров и $\mathrm{Ti}^{3+}$-примесей $[2,23]$. Из спектра ЭПР-нанокерамики также видно, что примесный $\mathrm{Mn}^{2+}$ имеет увеличенную на $10 \mathrm{G}$ константу СТС.

Детальный анализ крайней полосы СТС представлен на рис. 2. Видно, что сигнал СТС представляет собой суперпозицию как минимум двух сигналов $\left[\mathrm{Mn}^{2+}\right]_{\mathrm{Al}^{3+}}(1)$ и $\left[\mathrm{Mn}^{2+}\right]_{\mathrm{Al}^{3+}}$ (2). Среднее значение константы СТС (параметр $A$ ) составило $A_{1}=91.21 \mathrm{G}$ и $A_{2}=87.83 \mathrm{G}$ соответственно. Ввиду того, что полосы СТС, расположенные ближе к центру, имеют меньшую разницу перекрывающихся сигналов, то их сепарация возможна с большой ошибкой. Для расчета $A_{1}$ и $A_{2}$ использовались только первая и шестая компонента сверхтонкой структуры.

Влияние электронного облучения с энергией $130 \mathrm{keV}$ на сигнал ЭПР представлен на рис. 3.

В образцах регистрируется появление дополнительного сигнала с $g$-факторами: 2.007, 2.007, 2.005 для

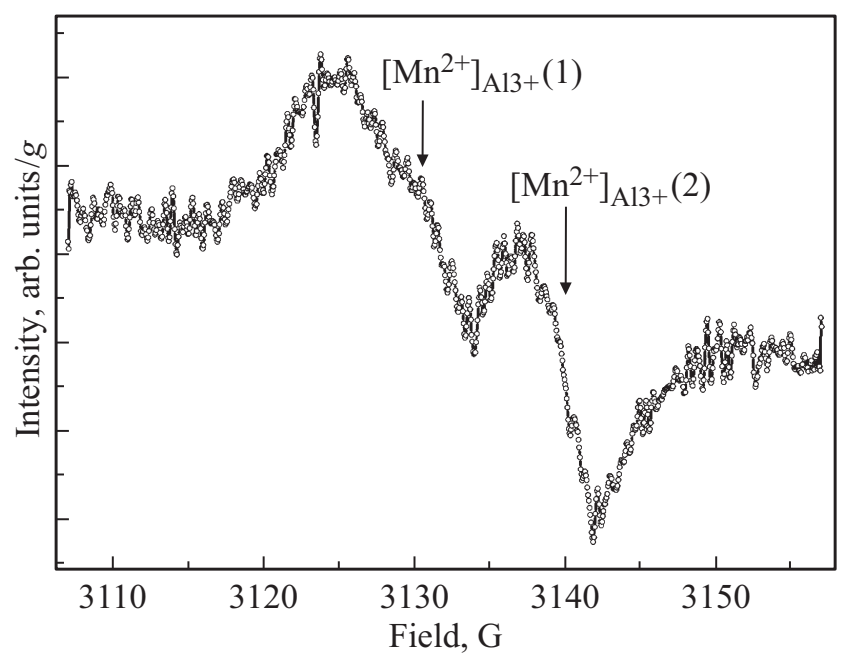

Рис. 2. Первая компонента СТС примесного $\mathrm{Mn}^{2+}$ в нанокерамике. Показано наличие двух сигналов, образующих полосу сверхтонкой структуры.

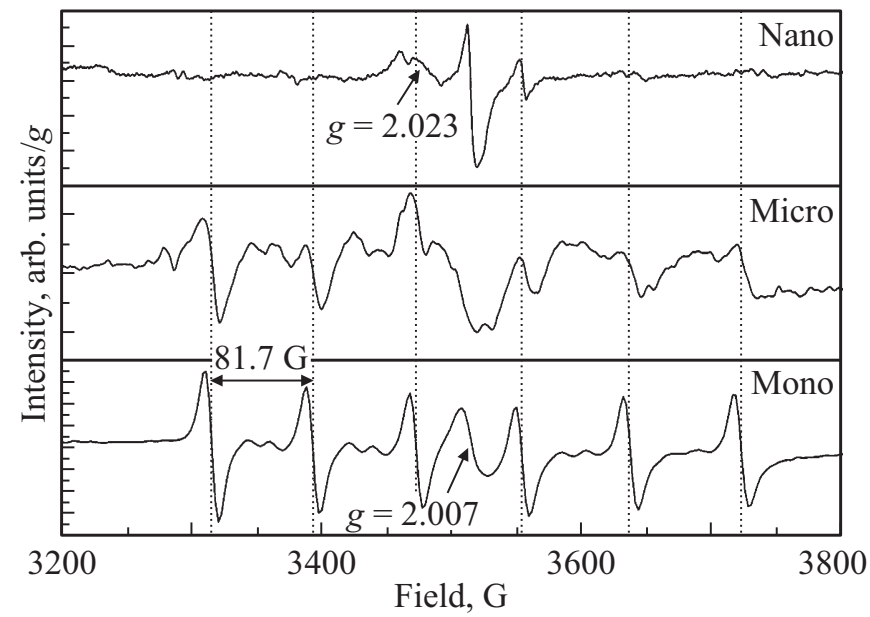

Pис. 3. Спектры ЭПР монокристаллического образца (Mono), микрокерамики (Micro) и нанокерамики (Nano) АМШ после облучения ускоренными электронами. Пунктирными линиями показаны характерные полосы СТС иона $\mathrm{Mn}^{2+}$. 
Таблица 2. Параметры СТС иона $\mathrm{Mn}^{2+}$ в моно, микро и нанокерамике АМШ

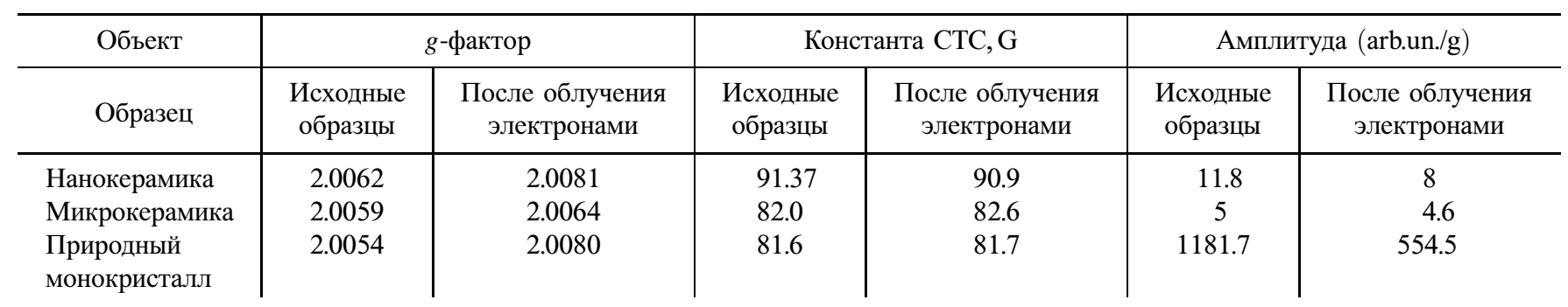

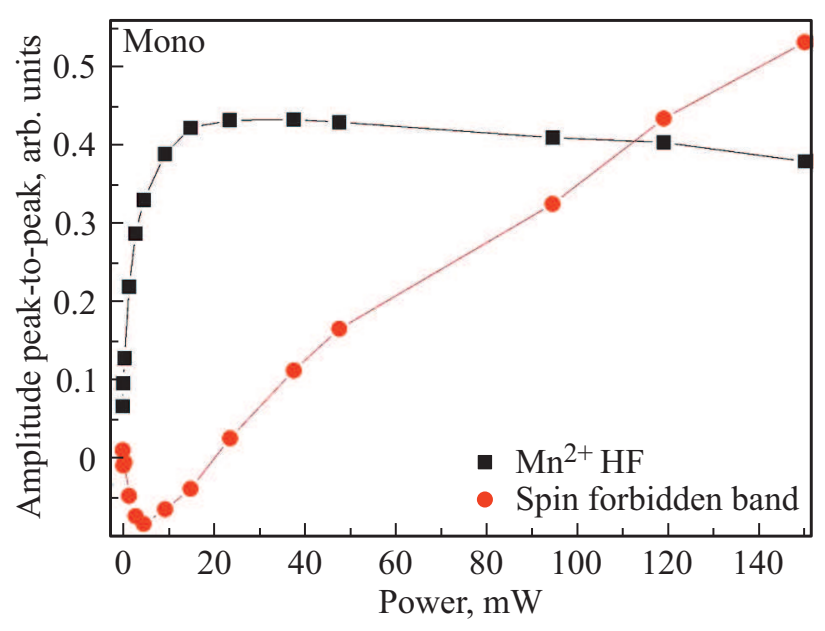

Рис. 4. Зависимость ЭПР-сигналов СТС монокристалла от мощности СВЧ-излучения.

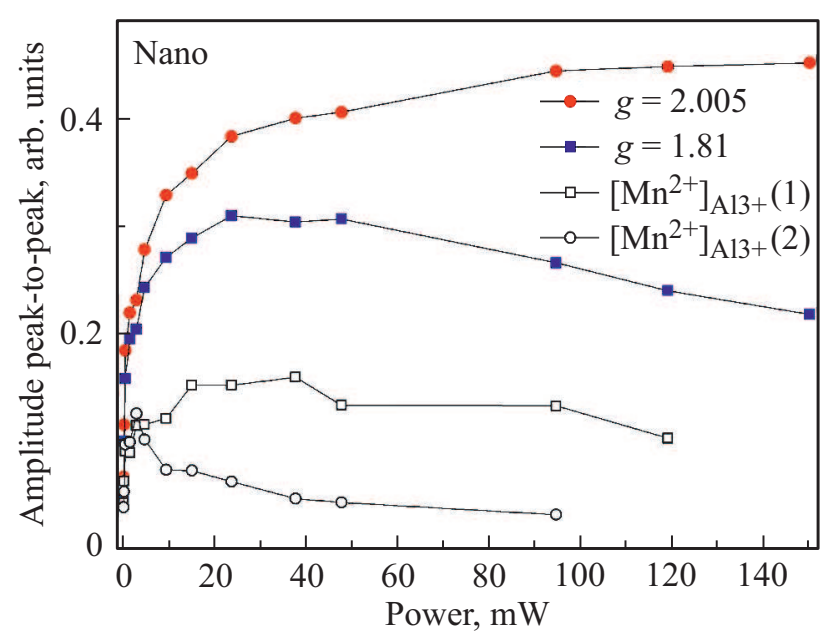

Рис. 5. Зависимость ЭПР-сигналов нанокерамики от мощности СВЧ-излучения.

монокристалла, микро- и нанокерамики соответственно. Во всех образцах отмечается снижение амплитуды полос СТC $\mathrm{Mn}^{2+}$. Дополнительной особенностью спектров ЭПР микро- и нанокерамики является появление широкого сигнала с $g=2.023$. Параметры СТС эталонов и нанокерамики АМШ до и после облучения электронами представлены в табл. 2. Видно, что облучение ускоренными электронами ведет к падению амплитуды сигнала СТC $\mathrm{Mn}^{2+}$, наибольшую чувствительность проявляет образец природного монокристалла. Регистрируется также изменение $g$-фактора и незначительное изменение параметра $A$. Мы не наблюдали каких-либо изменений в полуширинах линий СТС $(\Delta H)$.

Для оценки наблюдаемых изменений в полосе поглощения иона $\mathrm{Mn}^{2+}$ между монокристаллическим образцом и нанокерамикой спектры ЭПР СТС иона $\mathrm{Mn}^{2+}$ были записаны при различной мощности электромагнитного излучения. На рис. 4 представлены кривые зависимости интенсивности компонент СТС $\mathrm{Mn}^{2+}$ монокристалла от мощности СВЧ излучения. Насыщение разрешенных переходов СТC $\mathrm{Mn}^{2+}$ в монокристалле происходит при $15 \mathrm{~mW}$. В нанокерамике, ввиду того, что полоса СТC иона $\mathrm{Mn}^{2+}$ формируется за счет двух сигналов были определены две характерные мощности насыщения для $\left[\mathrm{Mn}^{2+}\right]_{\mathrm{Al}^{3+}}(1)$. и $\left[\mathrm{Mn}^{2+}\right]_{\mathrm{Al}^{3+}}(2)$, составившие $32 \mathrm{~mW}$ и $2.6 \mathrm{~mW}$ соответственно, рис. 5. Это позволяет сделать вывод о том, что наблюдаемые сигналы относятся к различным центрам. Характер зависимости кривой насыщения полосы с $g=1.981$ в нанокерамике совпадает с полосой $\mathrm{Mn}^{2+}$ в монокристалле, из чего следует, что часть сигнала связана со сверхтонкой структурой $\mathrm{Mn}^{2+}$. Судя по всему, в нанокерамике при указанном $g$-факторе происходит наложение сигналов. Насыщение сигнала $F^{+}$-центров по нашим оценкам происходит при $100 \mathrm{~mW}$. Полосы запрещенных переходов монокристаллического образца демонстрируют минимум при $5 \mathrm{~mW}$ на кривой зависимости интенсивности от мощности электромагнитного поля. Последующее увеличение мощности приводит к линейному росту интенсивности спин-запрещенных переходов.

\section{4. Обсуждение}

В работах [24,25] нами было показано, что в спектрах оптического поглощения прозрачных микро- и нанокерамик, подвергнутых электронной бомбардировке, регистрируются полосы, характерные для $F$ - и $F^{+}$-центров. Микрокерамика получена методом одноосного горячего прессования в графитовой пресс-форме, что по всей видимости послужило причиной возникновения анион- 
ных вакансий по механизму термохимического окрашивания [26]. В результате последующего облучения $130 \mathrm{keV}$ электронами происходит их локализация на анионных вакансиях. В нанокерамике в исходных образцах регистрируются ЭПР сигнал $F^{+}$-центров. Наличие анионных дефектов в нанокерамике объясняется низкой размерностью кристаллитов и как следствие большим количеством межзеренных границ. Такие границы сами по себе являются дефектами структуры с оборванными связями, в том числе кислородными вакансиями. Высокие давления стимулируют пластическую деформации зерен в результате которой происходит разрыв химических связей с последующим эмитированием электронов. Локализация электрона на анионной вакансии приводит к формированию в нанокерамике шпинели $F^{+}$-центра. Таким образом, при помощи термобарического синтеза можно имитировать высокоэнергетическое воздействие на матрицу шпинели.

Снижение амплитуды СТС в ЭПР спектре $\mathrm{Mn}^{2+}$ после облучения ускоренными электронами коррелирует с ростом сигнала от $F^{+}$-центров. В работе [13] авторы показывают, что в шпинели возможно образование комплексных дефектов, с участием как $F^{+}$-центра, так и антисайт дефектов. Однако механизм взаимодействия $F^{+}$-центра с примесным $\mathrm{Mn}^{2+}$ пока что под вопросом. Вероятно, при близком расположении $\mathrm{F}^{+}$-центров к примесному $\mathrm{Mn}^{2+}$ волновые функции локализованного электрона на $F^{+}$-центре и неспаренного электрона могут $\mathrm{Mn}^{2+}$ перекрываться.

Кривые насыщения позволяют не только разрешить перекрывающиеся сигналы ЭПР, но и оценить времена спин-решеточной $\left(T_{1}\right)$ и спин-спиновой $\left(T_{2}\right)$ релаксации. Методика расчета $T_{1}$ и $T_{2}$ приведена в работе [27]. По результатам расчетов установлено, что времена релаксации $F^{+}$-центра в нанокерамике составляют: $T_{1}=4.41 \cdot 10^{-4} \mathrm{~s} T_{2}=1.09 \cdot 10^{-8} \mathrm{~s}$.

По данным табл. 2 видно, что происходит незначительный сдвиг положения $g$-фактора СТС в зависимости от модификации кристаллической решетки (нано, микро или моно). Изменение $g$-фактора СТС $\mathrm{Mn}^{2+}$ между образцами в различном структурном состоянии связано с различной концентрацией собственных дефектов в анионной и катионной подрешетках. В работе [28] показано, что в результате сжатия матрицы шпинели происходит рост дефектов катионной подрешетки (антисайт дефектов). В нашем случае с образцах нанокерамики в результате закалки (резком сбросе давления и температуры) сохраняется сильное неравновесное состояние системы с большим количеством антисайт дефектов. Таким образом, по нашему мнению, наблюдаемый сдвиг $g$-фактора ЭПР сигнала СТС примесного $\mathrm{Mn}^{2+}$, обусловлен высокой концентрацией собственных дефектов матрицы.

Известно, что константа СТС в ЭПР-спектре примесного $\mathrm{Mn}^{2+}$ проявляет зависимость от доли ковалентности связи марганца, то есть от степени локализации электрона на ядре. Так, с падением до-

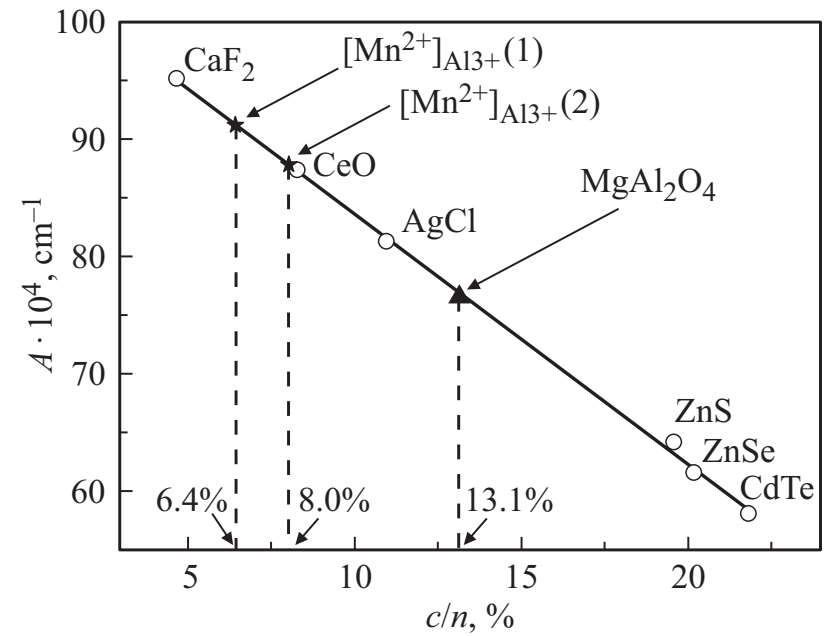

Рис. 6. Константа сверхтонкого расщепления $A$ в примесном $\mathrm{Mn}^{2+}$ как функция параметра ковалентности $c / n$ [18]. Звездочками показаны значения центров $\mathrm{Mn}^{2+}$ в нанокерамике. Треугольником - значение для монокристалла $\mathrm{MgAl}_{2} \mathrm{O}_{4}$ [18].

ли ковалентной связи параметр $A$ - растет. Например, CdTe: $A=55 \cdot 10^{4} \mathrm{~cm}^{-1} ; \mathrm{ZnS}: A=64 \cdot 10^{4} \mathrm{~cm}^{-1} ; \mathrm{MgO}$ : $A=81 \cdot 10^{4} \mathrm{~cm}^{-1} ; \mathrm{CaF}_{2}: A=96 \cdot 10^{4} \mathrm{~cm}^{-1}$ [18]. Основываясь на представленной в работе [18] зависимости параметра $A$ от $c / n$ (рис. 6), где $c$ - степень ковалентности (взята из выражения разницы электроотрицательностей примеси переходного металла и ее лиганда), $n$ - количество лигандов, проведена графическая оценка параметра ковалентности парамагнитных центров $\left[\mathrm{Mn}^{2+}\right]_{\mathrm{Al}^{3+}}$ (1) и $\left[\mathrm{Mn}^{2+}\right]_{\mathrm{Al}^{3+}}$ (2) в нанокерамике, составившая 6.4 и $8.0 \%$ соответственно. Применяя найденные значения параметра ковалентности можно уточнить количество лигандов по эмпирической формуле (1) [30].

$$
c=1-0.16\left(X_{A}-X_{B}\right)-0.035\left(X_{A}-X_{B}\right)^{2},
$$

где $X_{A}$ - электроотрицательность аниона, $X_{B}$ - электроотрицательность катиона. В случае с идеальным монокристаллом $\mathrm{MgAl}_{2} \mathrm{O}_{4}$ (без примесей и какихлибо структурных дефектов [18]) количество лигандов равно 4 (с небольшой погрешностью). Для центров $\left[\mathrm{Mn}^{2+}\right]_{\mathrm{Al}^{3+}}(1)$ и $\left[\mathrm{Mn}^{2+}\right]_{\mathrm{Al}^{3+}}(2)$ значение $n \sim 6$. В работе [31] также показано, что увеличение параметра $A$ может быть вызвано ростом координационного числа примесного марганца.

По всей видимости, дополнительное сжатие решетки и наличие значительной доли антисайт дефектов в нанокерамике приводит к тому, что примесный $\mathrm{Mn}^{2+}$, занимает преимущественное октаэдрические позиции. В результате этого неспаренный электрон в большей степени локализован на ядре $\mathrm{Mn}^{2+}$.

Наличие двух парамагнитных сигналов $\left[\mathrm{Mn}^{2+}\right]_{\mathrm{Al}^{3+}}(1)$ и $\left[\mathrm{Mn}^{2+}\right]_{\mathrm{Al}^{3+}}$ (2) указывает на два отличающихся по локальному окружению иона марганца. Ввиду того, что количество лигандов таких центров кратно шести, 

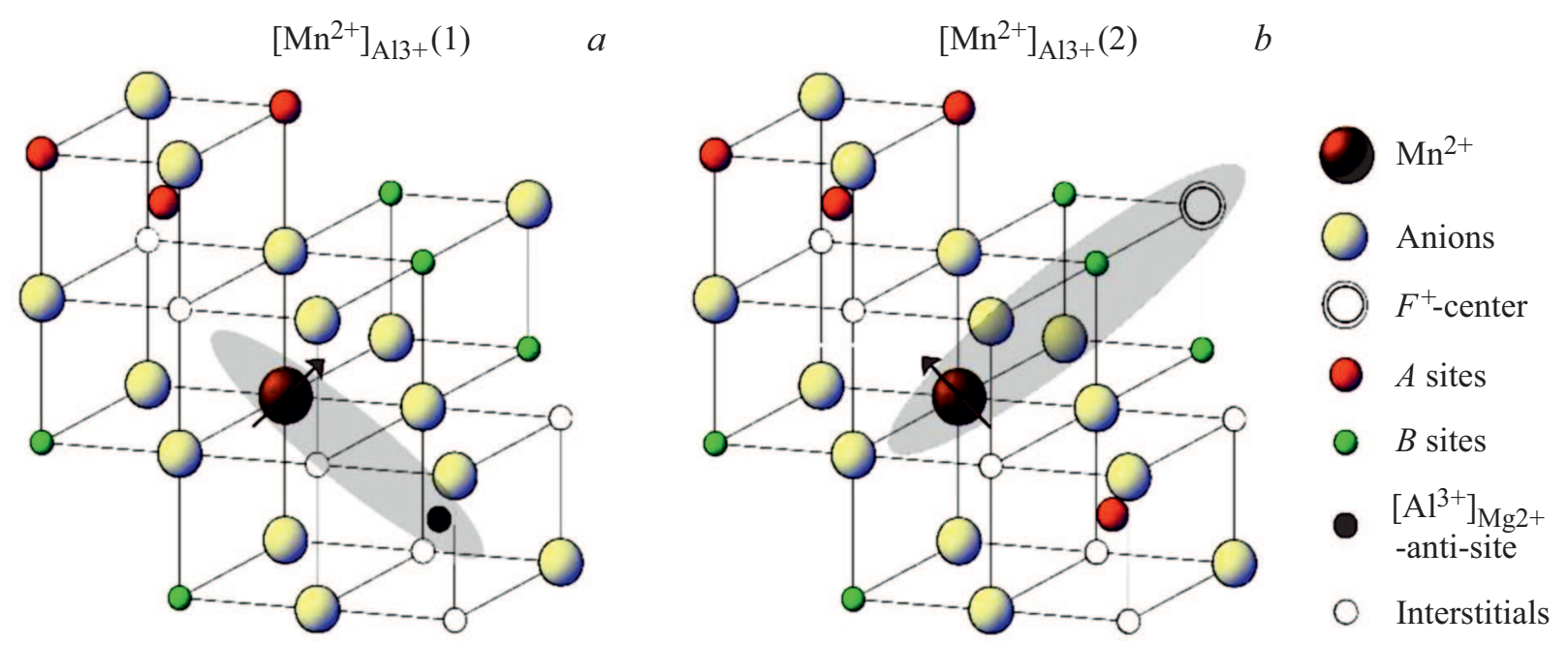

Рис. 7. Схема зарядовой компенсации примесного $\mathrm{Mn}^{2+}$ с участием антисайт дефекта $(a), F^{+}$-центра $(b)$. Серым цветом на схеме указано направление взаимодействия.

логично предположить компенсацию недостающего положительного заряда в узле через вторую координационную сферу. Один из наиболее вероятных механизмов компенсации заряда заключается в локализации антисайт дефекта, рис. 7, $a$. В таком случае заряд иона $\left[\mathrm{Mn}^{2+}\right]_{\mathrm{Al}^{3+}}$ будет скомпенсирован $\left[\mathrm{Al}^{3+}\right]_{\mathrm{Mg}^{2+}}$. В качестве альтернативного механизма компенсации заряда примесного $\mathrm{Mn}^{2+}$ в нанокерамике мы рассматриваем участие $F^{+}$-центров. Такой центр может выступать как зарядовый компенсатор октаэдрического $\mathrm{Mn}^{2+}$ во второй координационной сфере, рис. $7, b$.

Таким образом, наблюдаемые сигналы $\mathrm{Mn}^{2+}$ (1) и $\mathrm{Mn}^{2+}$ (2) на рис. 2 являются следствием наличия двух разных по окружению октаэдрических ионов $\mathrm{Mn}^{2+}$. Причем, ввиду того, что для $\left[\mathrm{Mn}^{2+}\right]_{\mathrm{Al}^{3+}}(1)$ величина параметра $A$ больше, то скорее всего в данном случае компенсация заряда реализуется с участием антисайт дефекта. В связи с чем, примесный $\mathrm{Mn}^{2+}$ в малых концентрациях в нанокерамике выполняет роль индикатора структурного состояния регулярных и нерегулярных (антисайт) позиций катиона $\mathrm{Mg}^{2+}$.

\section{5. Заключение}

Исследование парамагнитных центров алюмомагниевой шпинели в нанокерамике и ее микрокерамическом аналоге показывает, что в микрокерамике параметры примесных и собственных центров близки к монокристаллу. Это позволяет заключить, что значительные по размеру зерна могут рассматриваться в данном случае как отдельные микроскопические монокристаллы. В нанокерамике из-за низкой размерности и особенностей ее получения (термобарический синтез) возникают дополнительные искажения в решетке, приводящие к аномальным параметрам собственных и при- месных центров, таких как $F^{+}$-центры и $\mathrm{Mn}^{2+}$-центры. В качестве конкретных примеров можно выделить следующее:

1. Установлено, что исходные нанокерамики содержат значительную долю $F^{+}$-центров с $g=2.005$. После облучения электронами амплитуда указанного сигнала растет, регистрируется также появление широкого сигнала с $g=2.023$ неизвестной природы. Характерные времена спин-спиновой и спин решеточной релаксации $F^{+}$-центра составляют $1.09 \cdot 10^{-8} \mathrm{~s}$ и $4.41 \cdot 10^{-4}$ s соответственно.

2. Обнаружена аномальная константа СТС примесного $\mathrm{Mn}^{2+}$ связанная с шестикратной координацией по кислороду. Особенности спектроскопических параметров СТС марганцевых центров коррелируют с уменьшением параметра решетки в наноструктурном состоянии.

3. Сигналы СТС с $A_{1}=91.21 \mathrm{G}$ и $A_{2}=87.83 \mathrm{G}$ возникают благодаря зарядовой компенсации примесного $\mathrm{Mn}^{2+}$ с участием антисайт дефекта $\left[\mathrm{Al}^{3+}\right]_{\mathrm{Mg}^{2+}}$ и $F^{+}$-центра соответственно.

Совокупность полученных результатов позволяет заключить, что метод получения керамики оказывает существенное влияние на структурные свойства, открывая возможность управлять таковыми на микроуровне. Результаты исследования спектров ЭПР в диапазоне $\mathrm{CTC} \mathrm{Mn}^{2+}$ в матрице шпинели, полученной различными методами синтеза, представляют интерес для моделирования локальных взаимодействий примесного $\mathrm{Mn}^{2+} \mathrm{c}$ матрицей.

\section{Благодарности}

Выражаем благодарность Ю.В. Щаповой и Е.В. Гольевой за предоставленные образцы монокристалла и прозрачной микрокерамики АМШ. Отдельная благодарность В.А. Важенину за полезные дискуссии. 


\section{Финансирование работы}

Работа поддержана Министерством образования и науки (госзадание № 3.1485.2017/4.6) и Правительством Российской Федерации (акт 211, контракт № 02.A03.21.0006), а также проектом „Новые функциональные материалы для перспективных технологий“ № AAAA-A19-119031890025-9..

\section{Конфликт интересов}

Авторы заявляют, что у них нет конфликта интересов.

\section{Список литературы}

[1] J.M. Costantini, G. Lelong, M. Guillaumet, W.J. Weber, S. Takaki, K. Yasuda. J. Phys.: Condens. Matter 28, 325901 (2016).

[2] A. Ibarra, D. Bravo, M.A. Garcia, J. Llopis, F.J. Lopez, F. Garner. J. Nucl. Mater 258, 1902 (1998).

[3] G.P. Summers, G.S. White, K.H. Lee, Jr.J.H. Crawford. Phys. Rev. B: Condens. Matter 21, 2578 (1980).

[4] Ю. Казаринов, В. Кватчадзе, В. Грицина, М. Абрамишвили, 3. Акхвледианни, М. Галусташвили, Г. Деканозишвили, Т. Калабегишвили, Т. Тавкелидзе. Вопросы атомной науки и техники 5, 8 (2017).

[5] I.V. Afanasyev-Charkin, D.W. Cooke, V.T. Gritsyna, M. Ishimaru, K. Sickafus. Vacuum 58, 2 (2000).

[6] M. Ishimaru, Y. Hirotsu, I.V. Afanasyev-Charkin, K.E. Sickafus. J. Phys.: Condens. Matter 14, 1237 (2002).

[7] M. Ishimaru, Y. Hirotsu, K.E. Sickafus. Microscopy 51, 219 (2002).

[8] N. Kishimoto, Y. Takeda, N. Umeda, V.T. Gritsyna, C.G. Lee, T. Saito. Nucl. Instrum. Methods Phys. Res. B 166, 840 (2000).

[9] E. Hanamura, Y. Kawabe, H. Takashima, T. Sato, A. Tomita. J. Nonlinear Opt. Phys. Mater. 12, 467 (2003).

[10] V.T. Gritsyna, V.A. Kobyakov, L.A. Litvinov. J. Appl. Spectrosc. 45, 837 (1986).

[11] D. Valiev, S. Stepanov, O. Khasanov, E. Dvilis, E. Polisadova, V. Paygin. Opt. Mater. 91, 396 (2019).

[12] S. Sawai, T. Uchino. J. Appl. Phys. 112, 103523 (2012).

[13] A. Lushchik, S. Dolgov, E. Feldbach, R. Pareja, A.I. Popov, E. Shablonin, V. Seeman. Nucl. Instrum. Meth. Phys. Res. B. 435, 31 (2018).

[14] A. Navrotsky, O.J. Kleppa. J. Inorg. Nucl. Chem. 29, 2701 (1967).

[15] V. D’Ippolito, G.B. Andreozzi, D. Bersani, P.P. Lottici. J. Raman Spectrosc. 46, 1255 (2015).

[16] Y. Zou, D. He, X. Wei, R. Yu, T. Lu, X. Chang, S. Wang, L. Lei. Mater. Chem. Phys. 123, 529 (2010).

[17] J.S. Shaffer, H.A. Farach, JrC.P. Poole. Phys. Rev. B. 13, 1869 (1976).

[18] E. Simanek, K.A. Mueller. Chem. Phys. Lett. 4, 482 (1970).

[19] A.N. Kiryakov, A.F. Zatsepin, T.V. Dyachkova, A.P. Tytunyunnik, Y.G. Zainulin, G. Yakovlev, V.A. Pustovarov, D. Bautimirov. IOP Conf. Ser.: Mater. Sci. Eng. 443, 012014 (2018).

[20] B.H. Toby. J. Appl. Crystallogr. 34, 210 (2001).

[21] A.C. Larson, R.B. Von. Dreele Report 1AUR. 86 (1994).
[22] H. Maekawa, S. Kato, K. Kawamura, T. Yokokawa. Am. Mineral. 82, 1125 (1997).

[23] P. Lombard, B. Boizot, N. Ollier, A. Jouini, A. Yoshikawa. J. Cryst. Growth. 311, 899 (2009).

[24] A.N. Kiryakov, A.F. Zatsepin, Y.V. Shchapova, E.V. Golyeva, V.A. Pustovarov. KnE Mater. Sci. 4, 98 (2018).

[25] A.N. Kiryakov, A.F. Zatsepin, A.I. Slesarev, T.V. Dyachkova, Y.G. Zainulin, M. Mashkovtsev, G. Yakovlev, A.S. Vagapov. AIP Conf. Proc. - AIP Publishing. 2015, 020039 (2018).

[26] V. Kortov, S. Zvonarev, A. Kiryakov, D. Ananchenko. Mater. Chem. Phys. 170, 168 (2016).

[27] Ч. Пул Техника эпр-спектроскопии / Пер. с англ. Мир, М. (1970).

[28] F. Méducin, S.A. Redfern, Y. Le Godec, H.J. Stone, M.G. Tucker, M.T. Dove, W.G. Marshall. Am. Mineral. 89, 981 (2004).

[29] N.B. Hannay, C.P. Smyth. J. Am. Chem. Soc. 68, 171, (1946).

[30] JrF.W. Breivogel, V. Sarkissian. J. Chem. Phys. 48, 2442 (1968).

Редактор Д.В. Жуманов 